\title{
Spatial Distribution of Raffaelea quercivora in Xylem of Naturally Infested and Inoculated Oak Trees
}

\author{
Yukiko Takahashi, Norihisa Matsushita, and Taizo Hogetsu
}

Graduate School of Agricultural and Life Sciences, The University of Tokyo, 1-1-1 Yayoi, Bunkyo-ku, Tokyo 113-8657, Japan. Accepted for publication 30 March 2010.

\begin{abstract}
Takahashi, Y., Matsushita, N., and Hogetsu, T. 2010. Spatial distribution of Raffaelea quercivora in xylem of naturally infested and inoculated oak trees. Phytopathology 100:747-755.

Mass mortality of Japanese oak caused by Raffaelea quercivora due to Japanese oak wilt (JOW) has been tremendous since the late 1980s in Japan. We investigated detailed distribution of $R$. quercivora hyphae in a naturally infected Quercus serrata tree using fluorescein-conjugated wheat germ agglutinin and also examined spatial relationships between hyphal distribution, water conduction loss, and host reactions in xylem in inoculated $Q$. crispula saplings. Hyphae of $R$. quercivora elongated

longitudinally in vessels and transversely in ray tissues in both naturally infected and inoculated Quercus trees. Hyphae were confined within a relatively small area near the inoculation site. Vessel dysfunction was also confined and overlapped with hyphal distribution. The reaction zone consisting of two types of fluorescent substance was formed surrounding the outside of the hyphal area in xylem and was always found in nonwater-conductive zone. These results suggest that wilting of Quercus trees caused by JOW may not be induced by dysfunction of a small number of vessels, but by that of many vessels, and it requires that $R$. quercivora hyphae spread from many galleries bored by beetles during mass attacks.
\end{abstract}

Mass mortality of oak trees in Japan, mainly of Quercus crispula Blume and $Q$. serrata Thunb. ex Murray, due to Japanese oak wilt (JOW) has been tremendous since the late 1980s, especially in areas along the Japan Sea (14). In recent years, trees of both Quercus species covering an area of 1,000 ha have been lost each year (7).

In early summer, mass attack by an ambrosia beetle, Platypus quercivorus (Murayama) (Coleoptera: Platypodidae), against the Quercus trunk results in numerous galleries in the sapwood, in which beetle offspring are produced. Female beetles carry the causal fungus of JOW, Raffaelea quercivora Kubono \& Shin. Ito, in mycangia in the pronotum $(13,16,18)$ and introduce it into the gallery during the mass attack (17). The infested trees show dark discoloration of sapwood surrounding the galleries and nonwater-conducting vessels in the discolored sapwood $(19,20)$. Inoculation experiments with this pathogenic fungus to Quercus saplings also demonstrate that this fungus induces discoloration of xylem and severe loss of water conduction $(22,23,33)$.

Because the pathogenic fungus $R$. quercivora was frequently isolated from discolored but not from nondiscolored sapwood (13), discoloration should be related to the presence of pathogenic hyphae. The loss of water conduction might also be related to the presence of hyphae in the vessels. Although Kuroda (19) observed hyphae in vessels and ray cells of $R$. quercivora-infected sapwood of adult $Q$. crispula, detailed distribution of the fungus in the infested trees has not been examined. Detailed distribution of the pathogen within infected stem tissues may provide indispensable information for understanding the mechanism of the spreading process and the loss of water conduction.

In the above observation by Kuroda (19), thin sections were stained with safranin-fast green, but no information has yet been obtained on detailed pathogen distribution within infected tissues, probably because of the difficulty of detecting hyphae using

Corresponding author: Y. Takahashi; E-mail address: y_takah@fr.a.u-tokyo.ac.jp

doi:10.1094/PHYTO-100-8-0747

(C) 2010 The American Phytopathological Society safranin-fast green staining, which additionally stains host tissues. Hyphae of ascomycetes and basidiomycetes contain chitin, a polymer of $\mathrm{N}$-acetylglucosamine, in their cell wall that can intensely bind to lectins such as wheat germ agglutinin (WGA) (3). Because some angiosperms have binding sites for several fluorescein conjugates of such lectins only in the cell wall of differentiating tracheary elements and phloem cells (12), staining with these lectin conjugates would enable detection of fungal hyphae in angiosperm tissue much more easily. Fluorescein-conjugated WGA (F-WGA) has been used for staining cell walls of several fungal species using epifluorescence $(5,29)$. We have also applied F-WGA to thin sections of Mycopappus alni (Dearn. \& Barthol.) Redhead \& G. P. White infected Crataegus chlorosarca Maxim. foliar tissue and successfully detected intensely fluorescent hyphae in the dark background of the host tissue (30). This method may also make detection of hyphal distribution in $R$. quercivorainfected Quercus xylem tissue much more convincing and simple.

In this study, we investigated detailed distribution of $R$. quercivora hyphae in a naturally infected $Q$. serrata tree using FWGA staining and also examined spatial relationships between hypha distribution, water conduction loss, and host reactions in xylem in inoculated $Q$. crispula saplings.

\section{MATERIALS AND METHODS}

Sampling of a naturally infected $Q$. serrata tree. A $Q$. serrata tree (20-m high, $25-\mathrm{cm}$ stem basal diameter) attacked by $P$. quercivorus in the previous summer was cut down from a deciduous forest in the University Forest in Aichi, the University of Tokyo, on 25 April 2008, and a disk, $10 \mathrm{~cm}$ thick, was cut from the trunk at $1 \mathrm{~m}$ above the ground. The tree was weakened but still alive, and most of the sapwood in the disk was not discolored. Two xylem blocks were excised from the inside of the disk, as they included galleries of $P$. quercivorus. One was trimmed to a $2-\mathrm{cm}$ cube to include discolored and nondiscolored sapwood and was divided into 30 completely discolored and 11 partially discolored pieces of sapwood for fungal isolation. The other section was trimmed to a rectangular parallelepiped of $2 \times$ 
$1 \times 1 \mathrm{~cm}$, with a surface plane cut transversely across a $P$. quercivorus gallery at its center, fixed in a formalin fixative $(20 \%$ formalin, $10 \%$ dimethylsulfoxide, $0.1 \%$ Nonidet P-40, and $50 \mathrm{mM}$ sodium phosphate buffer (PB) $[\mathrm{pH} 7.0]$ ) for more than 10 days, and used for anatomical inspection.

Inoculation experiments with $Q$. crispula saplings. $R$. quercivora strain FB131 isolated from a dead $Q$. crispula tree in Daigonji Highland, Tokamachi, Niigata Prefecture was used for inoculation experiments. Toothpicks with proliferated $R$. quercivora hyphae were prepared as inocula; birch toothpicks $(65 \mathrm{~mm}$ long, $2 \mathrm{~mm}$ in diameter) were wetted with distilled water, autoclaved at $121^{\circ} \mathrm{C}$ for $20 \mathrm{~min}$, placed on the $R$. quercivora mycelium that had been grown on potato dextrose agar (PDA) (Eiken Chemical) plates for a week at $20^{\circ} \mathrm{C}$ in the dark, and incubated for a further 2 weeks under the same conditions. Three-year-old $Q$. crispula saplings grown on field soil in polypropylene pots (29 $\mathrm{cm}$ diameter $\times 23 \mathrm{~cm}$ high, 7.5 liter) were inoculated with the toothpicks on 9 to 11 June 2008 at Koishikawa Arboretum of the University of Tokyo. A hole was bored through the stem of each $Q$. crispula sapling at a height where the diameter was 0.9 to $1.0 \mathrm{~cm}$ using a $70 \%$ ethanol-sterilized drill tip ( $2.7 \mathrm{~mm}$ diameter), and an inoculum toothpick was inserted into the hole. After removing the extrusion of the toothpick from the hole, the inoculation site was sealed with paraffin-polyethylene film (Celpara tape, Daicel Chemical Industries) to avoid drying and fungal contamination from outside. $R$. quercivora-proliferated toothpicks were inoculated into 12 saplings, and sterile toothpicks without the pathogen into 12 as controls. At 4, 7, 14, and 28 days after inoculation (DAI), three inoculated and three control saplings were sampled for water conduction measurement, fungal reisolation, and anatomical observations.

Water conduction measurements. Each sapling was cut off under water at $15 \mathrm{~cm}$ below the inoculation hole, and its base was soaked in a dye solution $(0.1 \%$ acid fuchsin and $0.1 \%$ safranin $\mathrm{O})$ for more than $12 \mathrm{~h}$. After removal of all branches and leaves from the main stem, 1-cm-long segments were excised from the stem portion $10 \mathrm{~cm}$ above to $10 \mathrm{~cm}$ below the inoculation hole. Each segment was cut in half longitudinally (the cut surface was perpendicular to the inoculation hole), and dye-stained areas on longitudinal and transverse cut surfaces were observed and recorded under a Leica stereomicroscope (MZ16) equipped with a Leica digital camera system (DFC480).

Two halves from each segment in which either upper or below transverse surface showed a non-dye-stained xylem area, i.e., the non-water-conductive zone, were further divided longitudinally into four quarters. One section was divided into three pieces for fungal reisolation; the other three sections were fixed in the formalin fixative for anatomical observation, as mentioned above, after marking the direction to the inoculation hole with a razor blade.

Fungal isolation from a naturally infected tree and reisolation from inoculated saplings. For fungal isolation and reisolation, pieces from each sample were surface-sterilized with a sodium chlorate solution (available chlorine 1\%) for $2 \mathrm{~min}$, airdried on sterile filter paper, and incubated on malt extract agar (MA; $2 \%$ malt extract and $1.5 \%$ agar) plates for 7 days at $20^{\circ} \mathrm{C}$ in the dark. The presence of $R$. quercivora in each piece was determined by mycelial fungal proliferation around it: colony appearing with an indistinct margin, water-soaked, mucilaginous, and aerial mycelium exiguous was identified as $R$. quercivora.

Anatomy. The fixed samples were washed twice with $50 \mathrm{mM}$ PB, embedded into Tissue-Tek O.C.T. Compound (Sakura Finetek), frozen in a deep freezer, and set on a Leica cryostat microtome (CM 1500). Thin sections produced were 10-to 30- $\mu \mathrm{m}$ thick. After several rinses with $10 \mathrm{mM}$ PB to remove the embedding medium, sections were immersed in $10 \% \mathrm{KOH}$ for $10 \mathrm{~min}$ at room temperature and washed three times with $10 \mathrm{mM}$ PB. After incubation in a $2 \%$ bovine serum albumin (BSA) solution in $10 \mathrm{mM}$ PB for $30 \mathrm{~min}$ and three washes with $0.05 \%$ Tween 20 (= polyoxyethylene(20)sorbitan monolaurate; Wako) in $10 \mathrm{mM} \mathrm{PB}$, they were immersed in F-WGA solution $(0.01 \%$ F-WGA [Sigma], $1 \% \mathrm{BSA}$, and $10 \mathrm{mM} \mathrm{PB}$ ) for $1 \mathrm{~h}$, washed three times with $0.05 \%$ Tween 20 in $10 \mathrm{mM} \mathrm{PB}$, and mounted on a slide glass with Mowiol mounting medium (25\% glycerol, $10 \%$ Mowiol 4-88 [Calbiochem], 5\% 1,4-diazabicyclo[2.2.2] octane, and $0.1 \mathrm{M}$ Tris- $\mathrm{HCl}$ [pH 9.0]).

Microscopy and image processing. Mounted thin sections were observed with an Olympus epifluorescence microscope system (BH2-RFL-T3 and BX50) equipped with U-MWU (excitation, 330 to $385 \mathrm{~nm}$; emission, $420 \mathrm{~nm}$ ) and U-WIB (excitation, 460 to $490 \mathrm{~nm}$; emission, $510 \mathrm{~nm}$ ) mirror units. Images were recorded with an Olympus digital camera system (PD71). Photographs of small areas were taken at a high magnification under visible light, U-excitation, and IB-excitation to cover the whole area within each thin section and then merged to overlapped composites for both excitation modes using Adobe Photoshop CS3. The image contrast and brightness were adjusted between neighboring photographs, if necessary. The composites were superimposed on the stereomicroscopic photograph of the transverse cut surfaces of the segment, which was previously taken at a lower magnification for observation of the non-waterconductive zone as mentioned above. The non-water-conductive zone, the F-WGA-stained mycelial area, and U- and IB-excited bands were traced on the monitor.

Statistical analyses. On each of above superimposed transverse images, two lines were drawn perpendicularly from both edges of the marginal curve of the non-water-conductive zone to the inoculation hole. The area surrounded by the two lines, the marginal curve and the margin of the inoculation hole was measured, and divided by the length between intersections of the margin of the inoculation holes and the two lines to calculate the average width. The average width was also calculated for the FWGA-stained mycelial area in the same way. The axial length of non-water-conductive zone was estimated from observations of transverse surfaces of 1-cm-long segments. The segment in which the non-water-conductive zone was detected on bottom transverse surface but not on top one should contain the top edge of the nonconductive zone. Thus, the axial length of the non-water-conductive zone was estimated as the distance from the bottom of the segment to the inoculation hole. The axial length of the F-WGAstained mycelial area from the inoculation hole was measured in longitudinal thin sections that covered up to $2 \mathrm{~cm}$ from the inoculation hole.

Differences in widths of the non-water-conductive zone and the F-WGA-stained mycelial area, and length of the F-WGA-stained mycelial area between inoculated and noninoculated saplings were statistically tested by Student's $t$ test $(P<0.05)$ using SPSS Advanced Statistics 17.0. When axial length of the F-WGAstained mycelial area exceeded $2 \mathrm{~cm}$, the length was represented by $2 \mathrm{~cm}$ for statistic calculation.

\section{RESULTS}

$\boldsymbol{R}$. quercivora hyphae and wood reactions in a naturally infected $Q$. serrata tree. $R$. quercivora was isolated from all 30 pieces from the completely discolored sapwood and in 6 of 11 pieces from partially discolored sapwood. The pieces in which $R$. quercivora was absent contained no discoloration, suggesting that $R$. quercivora was present only in the discolored portion.

After F-WGA staining, green fluorescent hyphae were observed only in discolored sapwood, but not in heartwood under IB excitation (Fig. 1C and E). Most hyphae elongated longitudinally in vessels and transversely in ray tissues (Fig. 1C and E). More than $1 \mathrm{~cm}$ above and below the gallery, dark brown or black areas containing the clump of hyphae were observed in the tissue 
around broad vessels (Fig. 1A, B, and F). Tyloses in heartwood were colorless under visible light, bluish-white under U excitation, and yellow under IB excitation (Fig. 1C). In heartwood, a nonfluorescent, pale brown substance was observed in rays.

$\boldsymbol{R}$. quercivora hyphae and wood reactions in inoculated $Q$. crispula seedlings. Water conduction loss. No saplings wilted or died throughout the experiment. As the edge of a non-waterconductive zone was clear on the transverse cut surface, but obscure on the longitudinal surface, after absorption of the dye solution, the zone was identified by observing only the transverse cut surface. Longitudinal water conduction was inhibited through segments both above and below the inoculation hole in all saplings examined in this experiment (Fig. 2). In all noninoculated saplings, except in a 28-DAI sapling (No. 22), the nonwater-conductive zone spread longitudinally up to $2 \mathrm{~cm}$ just above and below the inoculation hole (Fig. 2B). In inoculated saplings, the non-water-conductive zone spread longitudinally up to $4 \mathrm{~cm}$ from the inoculation hole by $4 \mathrm{DAI}$, and more than $10 \mathrm{~cm}$
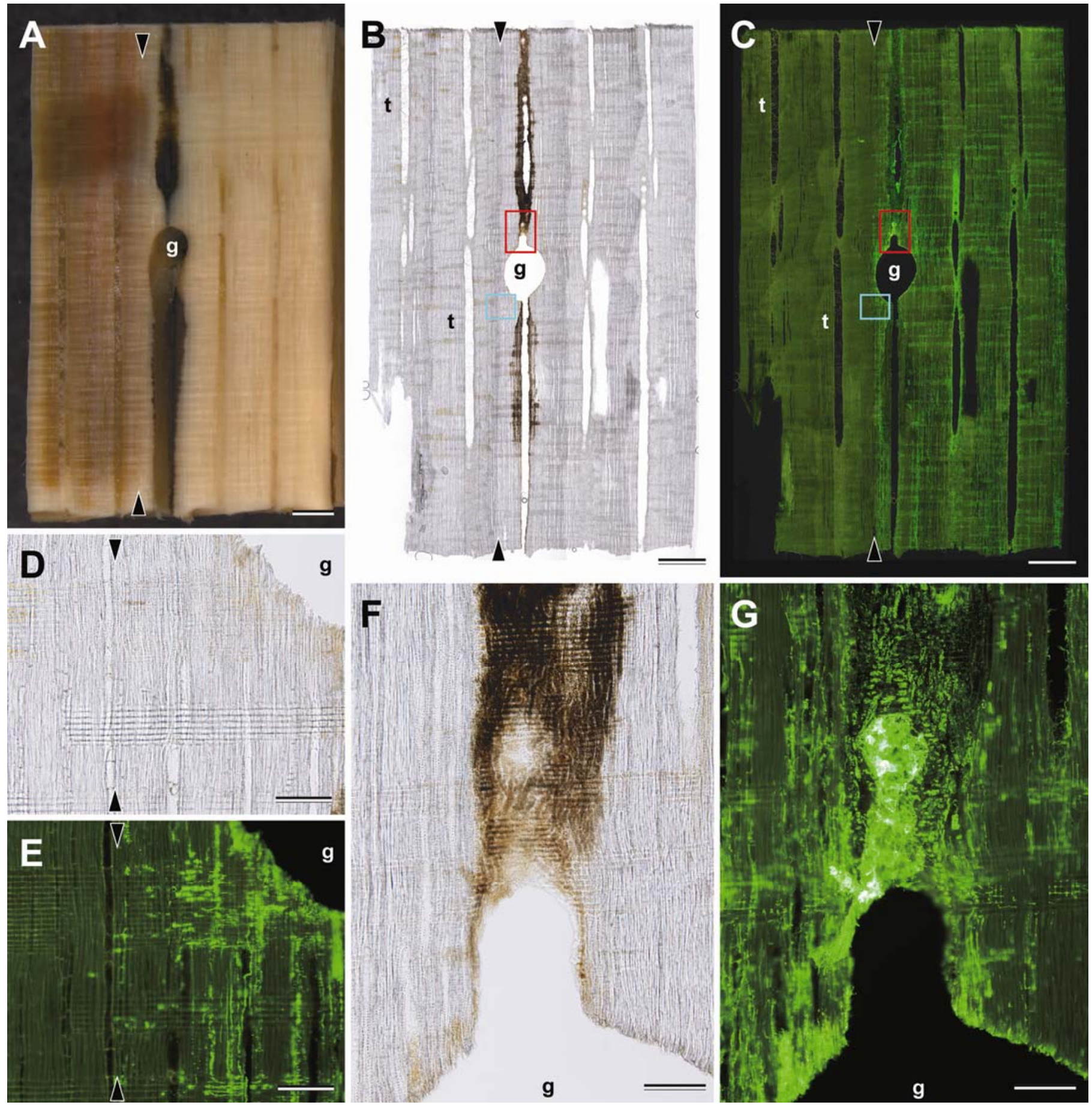

Fig. 1. Hyphal distribution around the gallery of Platypus quercivorus in naturally Japanese oak wilt-infested Quercus serrata wood. Thin sections were stained with fluorescein-conjugated wheat germ agglutinin and observed under visible light and IB excitation. A, Radially cut surface of the wood. A gallery hole of $P$. quercivorus was present at the boundary between heartwood and discolored sapwood. B and C, Visible light and epifluorescence images of the same longitudinal thin-section. D and E, Magnifications of the light blue rectangle in $\mathbf{B}$ and $\mathbf{C}$, respectively. F and G, Magnifications of red rectangle in $\mathbf{B}$ and $\mathbf{C}$. Note that hyphae were partially pigmented in dark brown or black in $\mathbf{F}$, and fluoresced green under IB excitation in $\mathbf{G}$. Green fluorescent hyphae were distributed in sapwood, but not in heart wood. Arrowhead indicates the boundary between sapwood (right side) and heartwood (left side). g, gallery hole; t, tyloses. Bars in A, B, and C, $2 \mathrm{~mm} ; \mathbf{D}, \mathbf{E}, \mathbf{F}$, and $\mathbf{G}, 200 \mu \mathrm{m}$. 
by 7 DAI (Fig. 2A). After 14 DAI, longitudinal lengths of the non-water-conductive zone varied among inoculated saplings. The axial length of the non-water-conductive zone in inoculated saplings was significantly larger than in noninoculated ones until 7 DAI (Table 1). The average width of the non-water-conductive zone in inoculated saplings was larger than in the noninoculated one, although there was no significant difference between the widths in inoculated and noninoculated saplings at any DAI (Fig. 3; Table 1).

Reisolation and hyphal distribution of $\mathbf{R}$. quercivora. Except for a sapling on 4 DAI (No.1), R. quercivora was reisolated from segments including the inoculation hole from all inoculated saplings, but not from any noninoculated saplings (Fig. 2). Filamentous fungi of similar mycelial appearance to Phoma spp. or Phomopsis spp. were also isolated from samples of both noninoculated and inoculated saplings.

In noninoculated saplings, longitudinal and horizontal hyphal extensions from the hole were limited to the vicinity of the inoculation hole, even at 28 DAI (Figs. 3 and 4B; Table 1). In inoculated saplings, however, hyphae extended from the inoculation hole at 4 DAI (Figs. 3 and 4A). The hyphal extension ceased longitudinally and horizontally after 7 DAI (Figs. 2A, 3, and 4A; Table 1). The axial length of the mycelial areas in inoculated saplings was significantly larger than in noninoculated ones
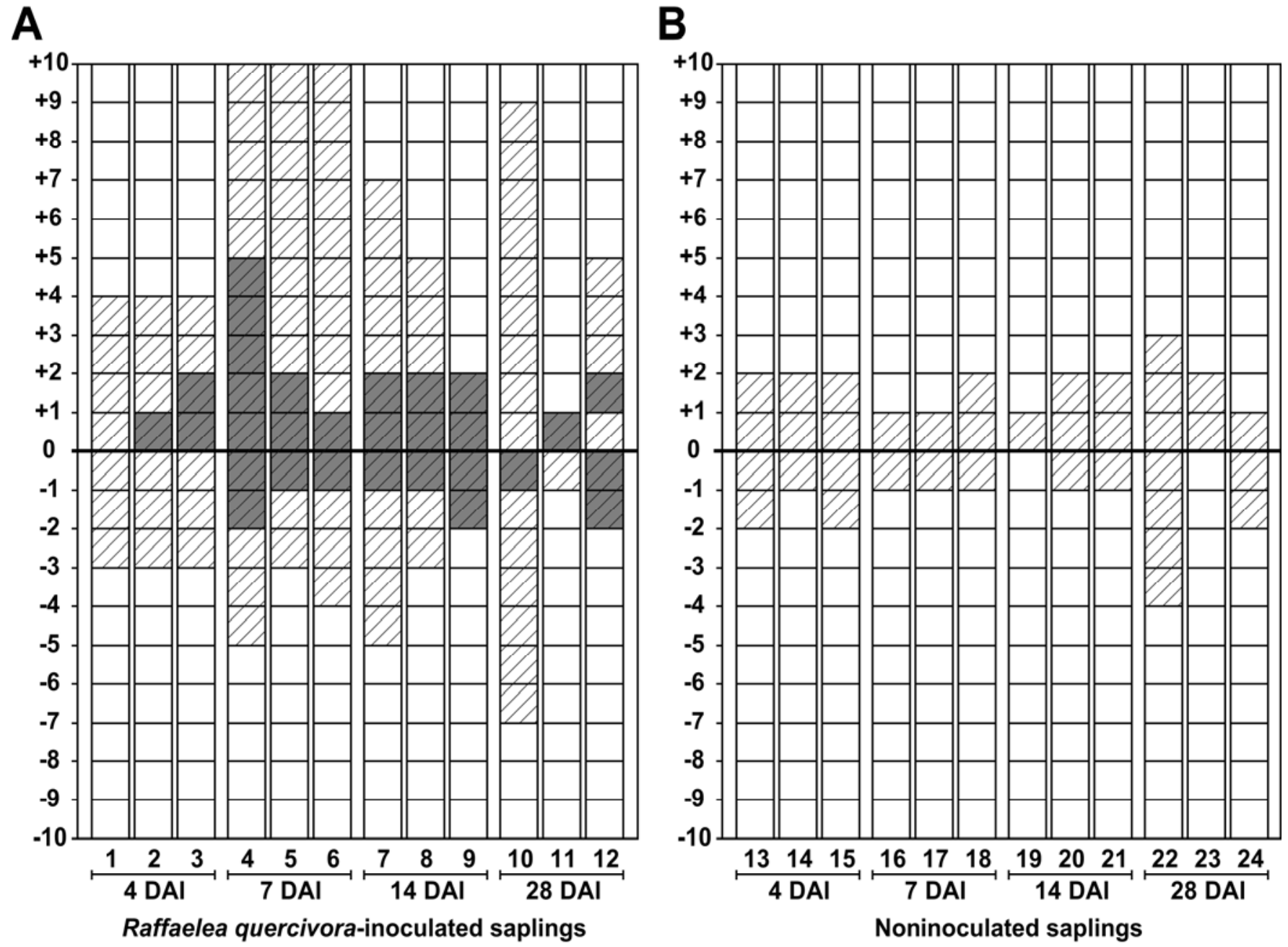

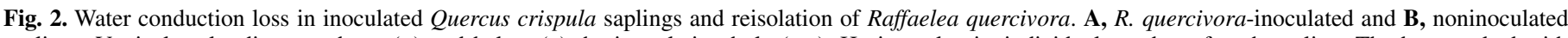

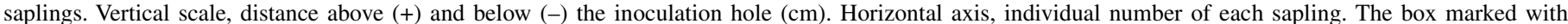

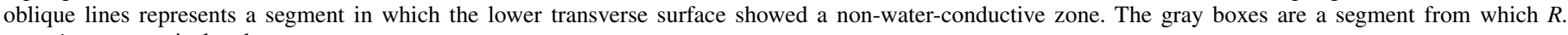
quercivora was reisolated.

TABLE 1. Mean length of non-water-conductive zone and hyphal distribution in Raffaelea quercivora-inoculated and noninoculated saplings

\begin{tabular}{|c|c|c|c|c|c|c|c|c|}
\hline \multirow{3}{*}{$\begin{array}{l}\text { Days after } \\
\text { inoculation }\end{array}$} & \multicolumn{4}{|c|}{ Non-water-conductive zone } & \multicolumn{4}{|c|}{ Hyphal distribution } \\
\hline & \multicolumn{2}{|c|}{ Longitudinal length $(\mathrm{cm})^{\mathrm{b}}$} & \multicolumn{2}{|c|}{ Horizontal length (mm) } & \multicolumn{2}{|c|}{ Longitudinal length $(\mathrm{cm})^{\mathrm{c}}$} & \multicolumn{2}{|c|}{ Horizontal length (mm) } \\
\hline & Inoculated & Noninoculated & Inoculated & Noninoculated & Inoculated & Noninoculated & Inoculated & Noninoculated \\
\hline 4 & $6.0 \pm 0.0 *$ & $2.7 \pm 0.6$ & $0.97 \pm 0.26$ & $0.61 \pm 0.27$ & $1.38 \pm 0.62 *$ & $0.05 \pm 0.03$ & $0.49 \pm 0.15^{*}$ & $0.08 \pm 0.09$ \\
\hline 7 & $13.0 \pm 1.0 *$ & $1.3 \pm 0.6$ & $1.03 \pm 0.29$ & $0.59 \pm 0.09$ & $1.40 \pm 0.23^{*}$ & $0.10 \pm 0.05$ & $0.48 \pm 0.09 *$ & $0.20 \pm 0.12$ \\
\hline 14 & $7.0 \pm 4.0$ & $1.3 \pm 1.2$ & $1.23 \pm 0.07$ & $0.65 \pm 0.39$ & $1.31 \pm 0.53^{*}$ & $0.18 \pm 0.11$ & $0.61 \pm 0.08$ & $0.37 \pm 0.38$ \\
\hline 28 & $7.3 \pm 7.1$ & $3.0 \pm 2.6$ & $1.06 \pm 0.20$ & $0.85 \pm 0.14$ & $0.98 \pm 0.26^{*}$ & $0.33 \pm 0.30$ & $0.55 \pm 0.07$ & $0.27 \pm 0.19$ \\
\hline
\end{tabular}

${ }^{a}$ Number of saplings $=3$. ${ }^{*}$ Indicates that the zone size (mean $\left.\pm \mathrm{SD}\right)$ was significantly more extensive than in noninoculated saplings $(t$ test, $P<0.05)$.

${ }^{\mathrm{b}}$ Saplings in which non-water-conduction occurred longer than observation range adopted maximum value $(+9 \mathrm{~cm})$

c Longitudinal hyphal distribution was measured on vertical sections ranged between 0 to $2 \mathrm{~cm}$. 
(Table 1). There was no significant difference in width between inoculated and noninoculated saplings after 14 DAI (Table 1).

A few thin hyphae were found only in the vicinity of the inoculation hole in noninoculated saplings throughout the experiment (Figs. 3, 4B, and 5F and H). In inoculated saplings, hyphae were densely distributed in vessels, ray parenchyma, and fibers in the vicinity of the inoculation hole (Fig. 5A) and sparsely in vessels and rays distant from the hole. Hyphae within vessels were two to three times thicker than those in the surrounding xylem tissue (Fig. 5B). The thick hyphae within vessels seemed to branch into fine hyphae (Fig. 5B), which invaded the ray parenchyma cells from the vessel through cross-field pits (Fig. 5C).

Composite pictures of the horizontal planes including the inoculation hole showed that the front of the hyphae was distributed apart from the border of the non-water-conductive zone by several millimeters in both noninoculated and inoculated saplings (Fig. 3).

Distribution of tyloses. A few tylosis buds that were too small to completely embolize vessels were found in two out of three inoculated saplings at $4 \mathrm{DAI}$, whereas no tyloses were found in control saplings (Fig. 4). Tyloses were found in sapwood of all inoculated and noninoculated saplings at 7 DAI, and thereafter, frequency and maturity of tyloses increased (Fig. 4). The tyloses in sapwood were present in the non-water-conductive zone. While tyloses in noninoculated saplings were positioned near the hole, those in inoculated saplings were usually near the front of hyphal distribution and above hyphal invasion in vessels (Figs. 4 and 5D and $\mathrm{E})$.

Distribution of fluorescent substances. Two types of fluorescent substance were formed in the non-water-conductive zone, as a layer surrounding hyphal distribution in inoculated saplings and inoculation holes in noninoculated saplings (Fig. 5G, H, and I).

A fluorescent substance (signified as IB-EFS) usually accumulated in fibers, appeared as dots in transverse sections (Fig. 5G and $\mathrm{H}$ ) and rods in longitudinal sections (Fig. 5E and $\mathrm{F}$ ), and fluoresced yellow and light blue under IB and $U$ excitation, respectively (Fig. 5H and I). The other substance usually accumulated in the cell wall and fluoresced light blue under $U$ excitation, forming a fluorescent zone (signified as U-EFZ) (Fig. 5I). IB-EFS was usually distributed within U-EFZ, but in some saplings, it was outside U-EFZ. U-EFZ sometimes included tyloses.

IB-EFS was observed in two of three inoculated (Nos. 5 and 6) but no noninoculated saplings at 7 DAI (Figs. 3 and 4). Simultaneously, discontinuous and faintly fluorescent U-EFZ was observed in all noninoculated but no inoculated saplings (Figs. 3 and 4). At 14 DAI, IB-EFS was observed in all noninoculated and
4 DAI
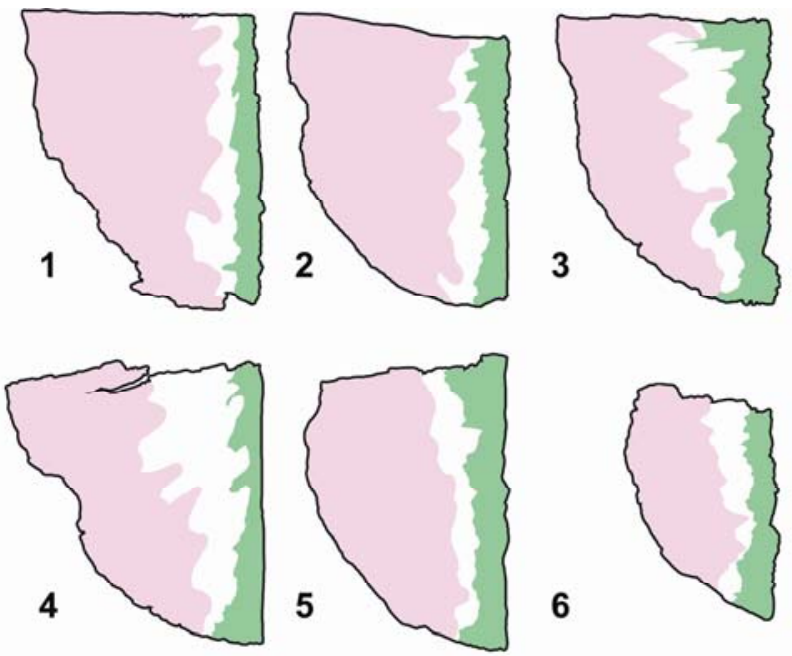

6

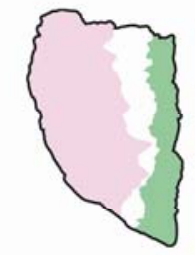

14 DAl

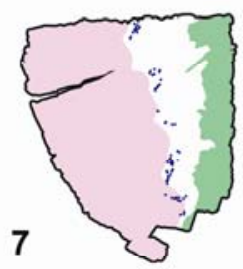

8
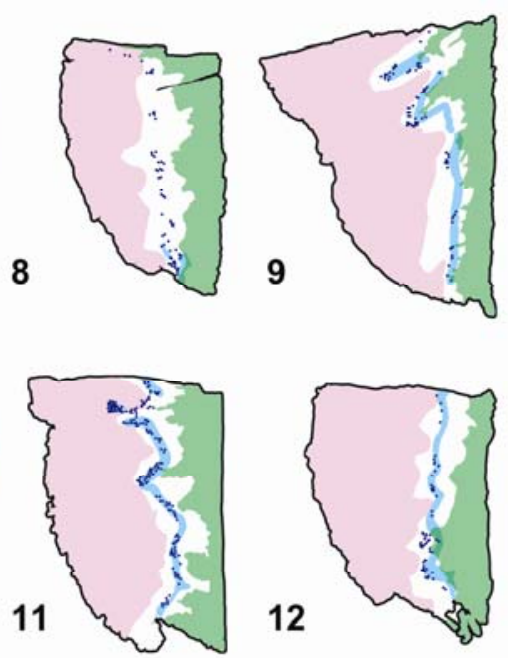

10

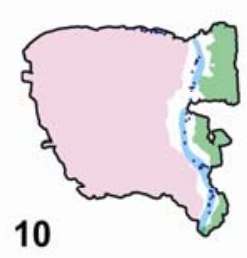

Raffaelea quercivora-inoculated saplings
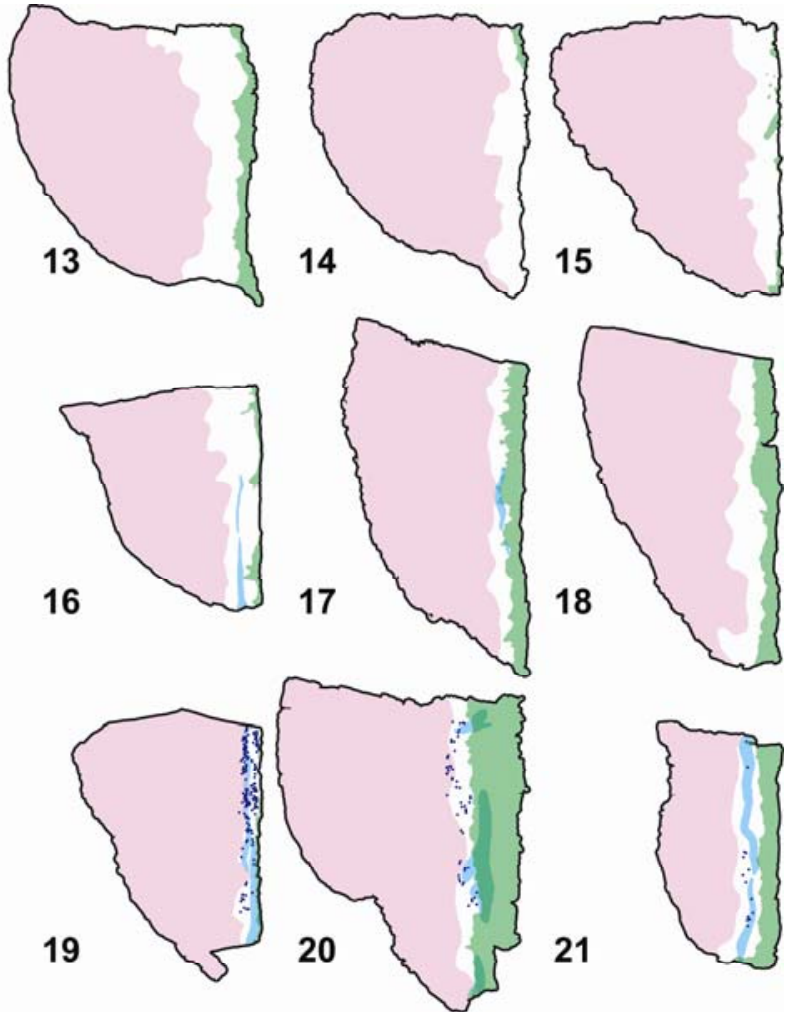

21
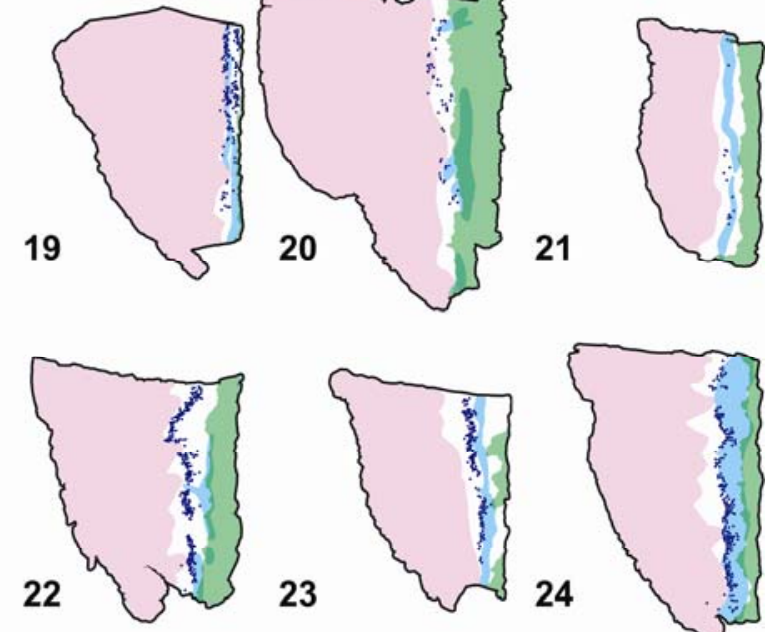

23
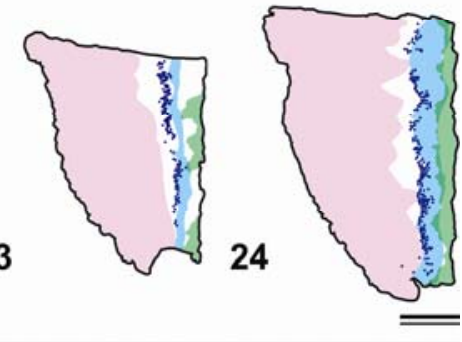

Noninoculated saplings

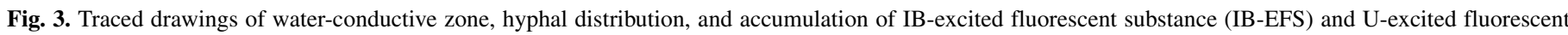

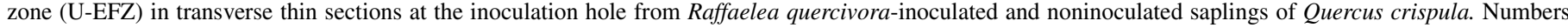

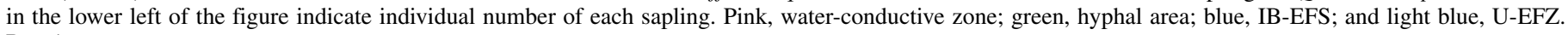
Bar, $1 \mathrm{~mm}$. 
inoculated saplings (Figs. 3 and 4B). U-EFZ was observed in all control saplings and one of three inoculated saplings (No. 9) (Figs. 3 and 4B). Both IB-EFS and U-EFZ with more intense fluorescence were observed in all saplings at 28 DAI (Figs. 3 and 4). In inoculated saplings, no hyphae intruded and penetrated the layer of IB-EFS and U-EFZ (Figs. 3 and 4A).

\section{DISCUSSION}

Hyphae stained with F-WGA were clearly observed in discolored sapwood around galleries of $P$. quercivorus in a naturally infected $Q$. serrata tree and in xylem of $R$. quercivorainoculated saplings. Because fluorescence from hyphae was much more intense than that from the host tissue, we could much more easily detect fungal hyphae in the host tissue than other conventional staining techniques. At present, staining with F-WGA may be the best technique to detect $R$. quercivora hyphal distribution in the host tissues. As almost no hyphae were found in noninoculated saplings, and fungi isolated from those infected tissues were mostly $R$. quercivora, we concluded that these hyphae were of $R$. quercivora.

Time-course observations of $R$. quercivora distribution in $R$. quercivora-inoculated saplings revealed the spread of $R$. quercivora in the xylem. Thick hyphae first extended vertically from the inoculum through vessels, branching into fine hyphae, and then the fine hyphae spread transversely in the ray parenchyma. Kuroda and Yamada (20) and Kuroda (19), using safranin-fast green staining, also observed that some hyphae are present in slightly discolored vessels and living xylem ray parenchyma cells in wilted $Q$. crispula trees attacked by $P$. quercivorus. Their observations are consistent with the present findings.

Structural and nutritional characteristics of Quercus xylem tissue might affect the pathway of spread of $R$. quercivora in the Quercus trunk. Because vessels of both Quercus species consist of nonliving cells with wide diameters that allow $R$. quercivora hyphae to enter easily, hyphae would first enter these vessels, as is observed in other wilt diseases, such as Dutch elm disease (DED) and Fusarium wilts (1). In these diseases, vessels also provide fungal pathogens with the main spreading pathway. Direct connections of rays with vessels through pits may facilitate the entrance of $R$. quercivora hyphae into the ray parenchyma from the vessels. Nutrients such as starch stored in the ray parenchyma (6) may also help pathogen spread into ray parenchyma.

Distribution of $R$. quercivora hyphae in inoculated saplings was confined vertically within a range of less than $5 \mathrm{~cm}$ from the inoculation site. The non-water-conductive zone caused by the infection was also confined to several millimeters beyond the hyphal distribution, roughly overlapping hyphal distribution. This indicates that $R$. quercivora hyphae evoke vessel dysfunction within a narrow distance. Yamato et al. (33) also showed, in
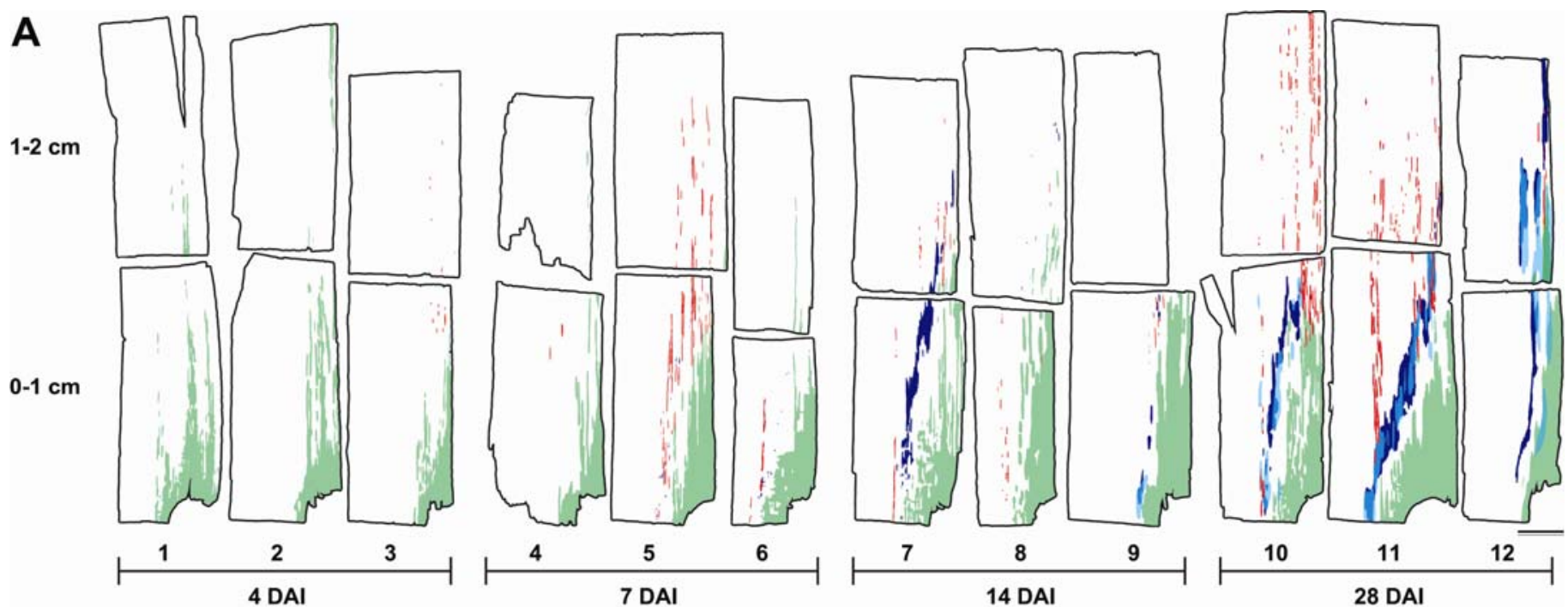

Raffaelea quercivora-inoculated saplings

B

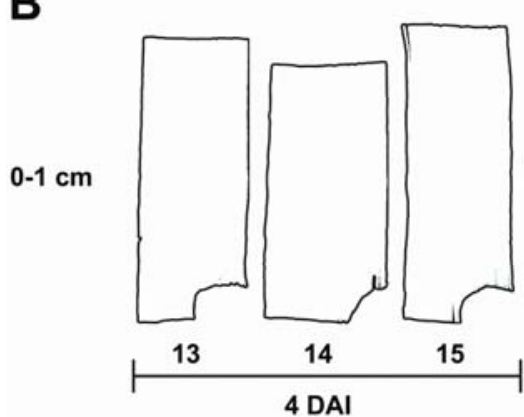

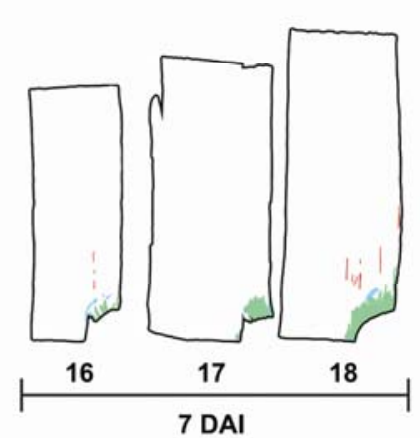
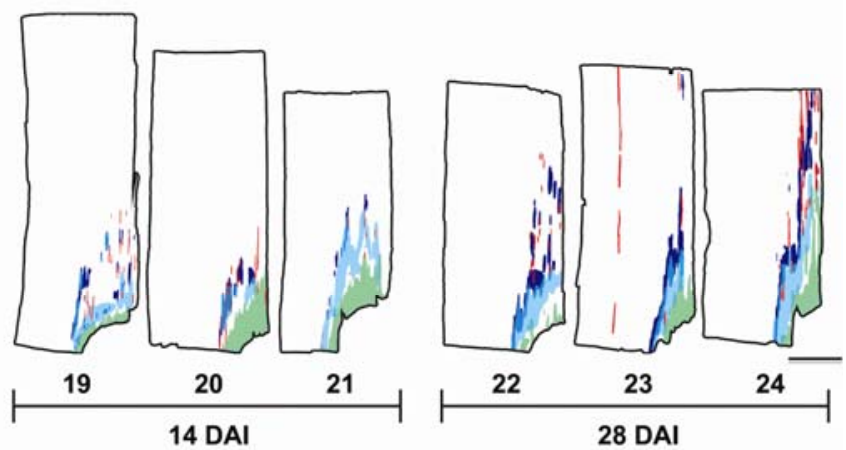

Noninoculated saplings

Fig. 4. Traced drawings of hyphal area, accumulation of IB-excited fluorescent substance (IB-EFS) and U-excited fluorescent zone (U-EFZ), and tylose

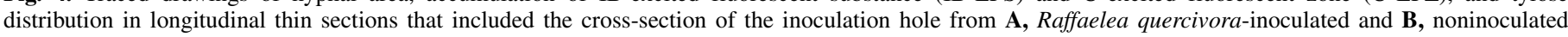

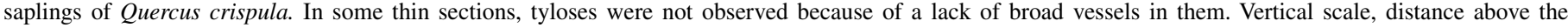

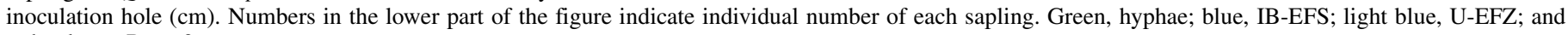
red, tyloses. Bars, $2 \mathrm{~mm}$. 

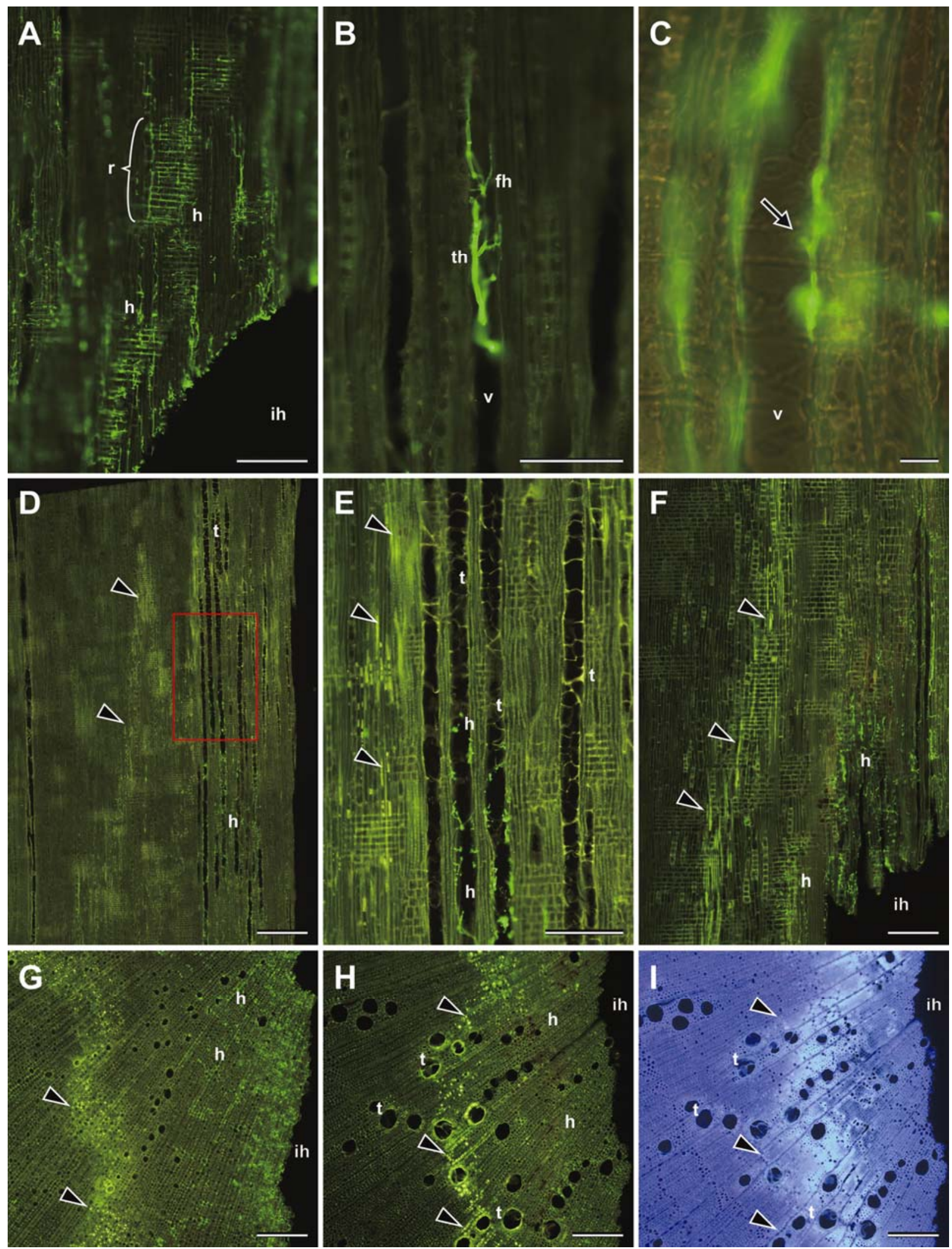

Fig. 5. Hyphae stained by fluorescein-conjugated wheat germ agglutinin (F-WGA) and fluorescent reaction zones in Raffaelea quercivora-inoculated and noninoculated Quercus crispula saplings. A, B, and C, F-WGA-stained hyphae in vessels and rays of an inoculated sapling at 4 days after inoculation (DAI) observed under IB excitation. A, Infected hyphae in xylem at low magnification. B, A thick hypha (th) of R. quercivora in a vessel with branching fine hyphae (fh). C, A hypha of $R$. quercivora within a vessel branched and invaded into ray parenchyma cells through a cross-field pit (arrow). D, E, and F, Radial thinsections of inoculated (D and $\mathbf{E}$ ) and noninoculated saplings (F) at 28 DAI. E, Magnification of the red rectangle in D. Note tyloses in vessels inhibiting hyphal extension (D and $\mathbf{E}$ ) and yellow rods of IB-excited fluorescent substance (IB-EFS) accumulated in fibers (F). G, H, and I, Transverse thin-sections of inoculated (G) and noninoculated (H and $\mathbf{I})$ saplings at 28 DAI. Yellow spots of IB-EFS formed a zone in $\mathbf{G}$ and $\mathbf{H}$. In inoculated sapling (G), hyphae of $R$. quercivora extended in ray, but not in noninoculated sapling $(\mathbf{H})$. I, The same sight as $\mathbf{H}$ under $\mathbf{U}$ excitation. Note that $\mathbf{U}$-excited fluorescent zone (U-EFZ) seen as light blue was nearer to the inoculation hole than IB-EFS (in H). Arrowhead, IB-EFS; h, hyphae; ih, inoculation hole; r, ray; t, tyloses; and v, vessel. Bars in A, E, F, G, H, and $\mathbf{I}, 200 \mu \mathrm{m} ; \mathbf{B}, 50 \mu \mathrm{m} ; \mathbf{C}, 10 \mu \mathrm{m}$; and $\mathbf{D}, 500 \mu \mathrm{m}$. 
inoculation experiments, that vessel dysfunction by $R$. quercivora is limited to the area around the inoculation site. Such spatial limitation of vessel dysfunction reflects $R$. quercivora hyphal distribution. Because the non-water-conductive zone occurred only around the $R$. quercivora distribution area, Quercus trees without mass infection by $R$. quercivora would not die. In fact, poly-inoculation of $R$. quercivora is necessary to experimentally kill Quercus trees $(13,24)$, and trees with a higher density of $P$. quercivorus galleries die faster (17). In this study, single inoculation into $Q$. crispula did not cause any host wilt or death.

No conidia or other propagules were detected among $R$. quercivora hyphae in both naturally infected trees and inoculated saplings. Such a specific fungal property may be a reason for the limited hyphal distribution of $R$. quercivora. In DED, the pathogen invades into the large vessels and produces conidia, which are carried upward by the sap flow and germinate and colonize at many sites (1). Repeats of this process result in systemic xylem dysfunction.

There are two types of wilt diseases caused by Ophiostomatoid fungi which are carried into the host tree by a vector beetle. In oak wilt disease caused by Ceratocystis fagacearum (Bretz) J. Hunt. and laurel wilt caused by $R$. lauricola T.C. Harr., Fraedrich \& Aghayeva, the pathogen carried into the host migrates through the vessels of the host and causes a systemic xylem dysfunction as in $\operatorname{DED}(8,11,15)$. Thus, the wilting mechanism of JOW is different from those of DED and laurel wilt. On the contrary, wilt diseases of conifer, which is caused by Ophiostomatoid fungi vectored by bark beetles, e.g., Dendroctonus ponderosa Hopkins (Scolytidae) (mountain pine beetle) and Ips typographus (L.) (Scolytidae) (European spruce bark beetle), shows no systemic symptom development, and frequent introductions of the fungal pathogen by massive attack from bark beetles is needed to kill the host tree $(10,21)$. JOW is the same as the latter type. In the wilt diseases of conifer, proliferation of the pathogen within the host tree might be also restricted to a narrow region by the defensive barrier as in JOW.

How $R$. quercivora hyphae evoke vessel dysfunction is not known. In DED, physical stimulation, such as piercing pits or perforation plates by hyphae, or chemical stimulation have been hypothesized as a trigger for vessel dysfunction $(2,25,26)$. In the present observations, hyphal penetration into a pit was observed. As mentioned above, however, the non-water-conductive zone caused by the inoculation expanded several millimeters beyond the hyphal distribution. This implies that the trigger is not a simple physical stimulation, like direct hyphal invasion through vessel pits, which would result in almost complete consistency of the vessel dysfunctional area with hyphal distribution.

Hyphal spread of $R$. quercivora provoked several defense reactions in Quercus xylem; tyloses developed at the edge of hyphal distribution. In $R$. quercivora-inoculated saplings, loss of water conduction preceded tylose development, as is generally recognized (31), and no hyphae penetrated the tyloses. These observations indicate that tyloses did not cause early dysfunction of xylem in JOW and block hyphal expansion. Tyree and Zimmermann (31) reported that tyloses seal off injured xylem that otherwise would serve as entry points for infection. Thus, these observations suggest that tylose formation is an effective defense response of Quercus trees against invasion by $R$. quercivora.

The reaction zone that consists of U-EFZ and IB-EFS was also formed surrounding the outside of the hyphal area in xylem at 28 DAI. As this reaction zone was observed in noninoculated saplings, its formation may be a common response of $Q$. crispula to wounding and/or fungal invasion. U-EFZ and IB-EFS were always found in the non-water-conductive zone. This suggests that these substances accumulated after the loss of water conductivity. As $R$. quercivora hyphae never extended across the zone of $\mathrm{U}-\mathrm{EFZ}$ and IB-EFS, this zone may have a repellent effect or be a physical barrier to invasion of $R$. quercivora, and the Quercus tree may confine $R$. quercivora inside of this reaction zone.

U-EFZ and IB-EFS were observed as light blue under excitation irradiation. As lignin and suberin are typical substances that fluoresce under UV $(365 \mathrm{~nm})$ in tree tissues (28), U-EFZ may include lignin and/or suberin. Yamada et al. (32) reported that insoluble deposits, including lignin-like compounds, pectin, phenolics, quinines, and lipids, occlude fibers in sapwood of $Q$. crispula and $Q$. serrata trees infected by $R$. quercivora. As some IB-EFS seemed to be gums or gels $(4,9,27)$ and were localized in fibers, the process might be the same as occurs with these insoluble deposits.

In conclusion, we successfully observed the detailed distribution of $R$. quercivora hyphae in JOW-infested Quercus trees using F-WGA staining and first revealed the positional relationships between $R$. quercivora hyphae, dysfunction of water conduction, and host defense reactions in JOW progression. $R$. quercivora hyphae spread mainly through vessels and ray parenchyma, are confined within a relatively small area near the inoculation site, and are surrounded by tyloses and layers of fluorescent substances. Vessel dysfunction is also confined and overlaps hyphal distribution. Unlike other wilt diseases, such as DED, wilting of Quercus trees caused by JOW may not be induced by dysfunction of a small number of vessels, but by that of many vessels, which requires spread of $R$. quercivora hyphae from many galleries bored by beetle mass attack.

\section{ACKNOWLEDGMENTS}

We thank K. Sasaki of Koishikawa Arboretum of the University of Tokyo for maintenance of the plants and the staff of the University Forest in Aichi, the University of Tokyo for help in sampling of the dead tree. This research was supported in part by the Japan Society for the Promotion of Science (JSPS) Research Fellowship for Young Scientists (No. 19-4584).

\section{LITERATURE CITED}

1. Agrios, G. N. 2005. Plant Pathology. 5th ed. Elsevier Academic Press, San Diego.

2. Binz, T., and Canevascini, G. 1996. Xylanases from the Dutch elm disease pathogens Ophiostoma ulmi and Ophiostoma novo-ulmi. Physiol. Mol. Plant Pathol. 49:159-175.

3. Carlile, M. J., Watkinson, S. C., and Gooday, G. W. 2001. The Fungi. 2nd ed. Academic Press, San Diego.

4. Clérivet, A., Déon, V., Alami, I., Lopez, F., Geiger, J.-P., and Nicole, M. 2000. Tyloses and gels associated with cellulose accumulation in vessels are responses of plane tree seedlings (Platanus $\times$ acerifolia) to the vascular fungus Ceratocystis fimbriata f. sp. platani. Trees-Struct. Funct. 15:25-31.

5. El Gueddari, N. E., Rauchhaus, U., Moerschbacher, B. M., and Deising, H. B. 2002. Developmentally regulated conversion of surface-exposed chitin to chitosan in cell walls of plant pathogenic fungi. New Phytol. 156:103-112.

6. Esau, K. 1977. Anatomy of Seed Plants. 2nd ed. John Wiley \& Sons, New York.

7. Forestry Agency. 2008. Shinrin-ringyo toukei youran (Woodland and forestry statistics handbook). Japanese Forestry Foundation, Tokyo (in Japanese).

8. Fraedrich, S. W., Harrington, T. C., Rabaglia, R. J., Ulyshen, M. D., Mayfield, A. E., III, Hanula, J. L., Eickwort, J. M., and Miller, D. R. 2008. A fungal symbiont of the redbay ambrosia beetle causes a lethal wilt in redbay and other Lauraceae in the southeastern United States. Plant Dis. 92:215-224.

9. Gagnon, C. 1967. Histochemical studies on the alteration of lignin and pectic substances in white elm infected by Ceratocystis ulmi. Can. J. Bot. 45:1619-1623

10. Harrington, T. C. 1993. Disease of conifers caused by species of Ophiostoma and Leptographium. Pages 161-172 in: Ceratocystis and Ophiostoma: Taxonomy, Ecology and Pathogenicity. M. J. Wingfield, K. A. Seifert, and J. F. Webber, eds. The American Phytopathological Society, St. Paul, MN.

11. Harrington, T. C., Fraedrich, S. W., and Aghayeva, D. N. 2008. Raffaelea lauricola, a new ambrosia beetle symbiont and pathogen on the 
Lauraceae. Mycotaxon 104:399-404.

12. Hogetsu, T. 1990. Detection of hemicelluloses specific to the cell wall of tracheary elements and phloem cells by fluorescein-conjugated lectins. Protoplasma 156:67-73.

13. Ito, S., Kubono, T., Sahashi, T., and Yamada, T. 1998. Associated fungi with the mass mortality of oak trees. J. Jpn. For. Soc. 80:170-175 (in Japanese with English abstract).

14. Ito, S., and Yamada, T. 1998. Distribution and spread of the mass mortality of oak trees. J. Jpn. For. Soc. 80:229-232 (in Japanese).

15. Jacobi, W. R., and MacDonald, W. L. 1980. Colonization of resistant and susceptible oaks by Ceratocystis fagacearum. Phytopathology 70:618-623.

16. Kinuura, H. 2002. Relative dominance of the mold fungus, Raffaelea sp., in the mycangium and proventriculus in relation to adult stages of the oak platypodid beetle, Platypus quercivorus (Coleoptera; Platypodidae). J. For. Res. 7:7-12.

17. Kinuura, H., and Kobayashi, M. 2006. Death of Quercus crispula by inoculation with adult Platypus quercivorus (Coleoptera: Platypodidae). Appl. Entom. Zool. 41:123-128.

18. Kubono, T., and Ito, S. 2002. Raffaelea quercivora sp. nov. associated with mass mortality of Japanese oak, and the ambrosia beetle (Platypus quercivorus). Mycoscience 43:255-260.

19. Kuroda, K. 2001. Responses of Quercus sapwood to infection with the pathogenic fungus of a new wilt disease vectored by the ambrosia beetle Platypus quercivorus. J. Wood Sci. 47:425-429.

20. Kuroda, K., and Yamada, T. 1996. Discoloration of sapwood and blockage of xylem sap ascent in the trunks of wilting Quercus spp. following attack by Platypus quercivorus. J. Jpn. For. Soc. 78:84-88 (in Japanese with English abstract).

21. Lieutier, F., Yart, A., and Salle, A. 2009. Stimulation of tree defenses by Ophiostomatoid fungi can explain attack success of bark beetles on conifers. Ann. For. Sci. 66:801.

22. Murata, M., Yamada, T., and Ito, S. 2005. Changes in water status in seedlings of six species in the Fagaceae after inoculation with Raffaelea quercivora Kubono et Shin-Ito. J. For. Res. 10:251-255.

23. Murata, M., Yamada, T., Matsuda, Y., and Ito, S. 2007. Discoloured and non-conductive sapwood among six Fagaceae species inoculated with Raffaelea quercivora. For. Pathol. 37:73-79.

24. Nakane, A., Murata, M., Sano, A., Matsuda, Y., and Ito, S. 2002. The examination on inoculation methods by Raffaelea sp. to Quercus serrata. Chubu For. Res. 50:109-112 (in Japanese).

25. Ouellette, G. B., Rioux, D., Simard, M., and Cherif, M. 2004. Ultrastructural and cytochemical studies of host and pathogens in some fungal wilt diseases: Retro- and introspection towards a better understanding of DED. Invest. Agrar. Sist. Recur. For. 13:119-145.

26. Richards, W. C. 1993. Cerato-ulmin: A unique wilt toxin of instrumental significance in the development of Dutch elm disease. Pages 89-151 in: Dutch Elm Disease Research: Cellular and Molecular Approaches. M. B. Sticklen and J. L. Sherald, eds. Springer-Verlag, New York.

27. Rioux, D., Nicole, M., Simard, M., and Ouellette, G. B. 1998. Immunocytochemical evidence that secretion of pectin occurs during gel (gum) and tylosis formation in trees. Phytopathology 88:494-505.

28. Ruzin, S. E. 1999. Plant Microtechnique and Microscopy. Oxford University Press, New York.

29. Schoffelmeer, E. A. M., Kils, F. M., Sietsma, J. H., and Cornelissen, B. J. C. 1999. The cell wall of Fusarium oxysporum. Fungal Genet. Biol. 27:275-282.

30. Takahashi, Y., Matsushita, N., Harada, Y., and Hogestu, T. 2008. Pathogenicity of frosty mildew fungus, Mycopappus alni, to tree species in five families and its infection site. Jpn. J. Phytopathol. 74:140-147 (in Japanese with English abstract).

31. Tyree, M. T., and Zimmermann, M. H. 2002. Xylem Structure and Ascent of Sap. 2nd ed. Springer, Berlin.

32. Yamada, T., Ichihara, Y., and Hori, K. 2006. Defense responses of oak trees against the fungus Raffaelea quercivora vectored by the ambrosia beetle Platypus quercivorus. Pages 132-135 in: Proceedings IUFRO Kanazawa 2003 "Forest insect population dynamics and host influences." Kanazawa University, Kanazawa.

33. Yamato, M., Yamada, T., and Suzuki, K. 2001. Wilt of oaks-Blockage of xylem sap ascent. Bull. Tokyo Univ. For. 106:69-76 (in Japanese with English summary). 